\title{
ADAPTAÇÃO DE UM ÍNDICE DE INTEGRIDADE BIÓTICA (IIB) COM PEIXES DE RIACHOS DO ALTO RIO SOROCABA (SP)
}

\section{Mariana de Aguiar Viana Maurício Cetra}

\section{Resumo}

Um bom gerenciamento dos recursos naturais aquáticos pode ser obtido utilizando-se um programa de monitoramento biológico. Este monitoramento pode ser realizado aplicando-se um Índice de Integridade Biótica (IIB). Este trabalho adaptou um Índice de Integridade Biótica (IIB) para os riachos da sub-bacia do Alto Rio Sorocaba utilizando dados das comunidades de peixes. A ictiofauna foi amostrada e dados ambientais foram coletados em 8 trechos de riachos. Os peixes foram classificados quanto à origem, posição na coluna d'água e categoria trófica. As 27 métricas candidatas foram examinadas quanto à amplitude, capacidade de resposta e redundância. Das métricas testadas, quatro foram selecionadas para compor o IIB. Elas pertencem aos atributos abundância, diversidade de espécies e estrutura trófica: proporção do número de indivíduos pertencentes à ordem siluriformes, proporção da riqueza de espécies de siluriformes, número de categorias tróficas e proporção do número de indivíduos omnívoros. Quatro riachos (50\%) foram classificados como regular e $37,5 \%$ foram classificados como bom. Em escala regional, por um longo prazo e com baixo custo o IIB pode ser utilizado como ferramenta de monitoramento biológico para gerenciamento dos riachos.

Palavras-chave: ictiofauna; biomonitoramento; bioindicadores; índice multimétrico.

\section{Abstract}

A good management of aquatic natural resources can be obtained by using a biological monitoring program. This monitoring can be performed by applying an Integrity Biotic Index (IBI). This work adapted an Integrity Biotic Index (IBI) for streams in the Alto Rio Sorocaba sub-basin using data from fish communities. The ichthyofauna was sampled and environmental data were collected in eight streambed sections. The fish were classified according to origin, position in the water column and trophic category. The 27candidate metrics were examined for range, responsiveness and redundancy. From the metrics tested, four were selected to compose the IBI. They belong to the attributes of abundance, species diversity and trophic structure: proportion of the number of individuals belonging to the order siluriformes, proportion of the richness of siluriformes, number of trophic categories and proportion of number of omnivorous individuals. Four streams (50\%) were classified as regular and $37.5 \%$ were classified as good. On a regional scale, for a long term and low cost, IBI can be used as a biological monitoring tool for river management.

Keywords: ichthyofauna; biomonitoring; bioindicators; multimetric index.

\section{INTRODUÇÃO}

Os ambientes aquáticos e sua biodiversidade tornam-se vulneráveis à medida em que se intensificam as interferências diretas nos recursos hídricos geradas por fatores como urbanização e adensamento populacional das cidades (AGOSTINHO; THOMAZ; GOMES, 2005).

Para um bom manejo dos recursos naturais, o monitoramento biológico pode ser uma ferramenta importante visto que ele poderá refletir a estrutura física, química e biológica dos ambientes. Desde o desenvolvimento do Índice de Integridade Biótica - IIB proposto por Karr (1981), utilizando atributos das comunidades de peixes para avaliar riachos do meio-oeste dos Estados Unidos, adaptaçóes foram reproduzidas em diversas regióes do mundo levando-se em consideração 
características intrínsecas locais e por meio da seleção de um conjunto de variáveis biológicas que foram utilizadas para categorizar as alteraçōes ambientais. Vários estudos adaptaram o índice baseando-se em comunidades de peixes (MARCIANO; CHAUDHRY; RIBEIRO, 2004; FERREIRA; CASATTI, 2006; CASATTI; FERREIRA; CARVALHO, 2009; ESTEVES; ALEXANDRE, 2011; CASATTI et al., 2012; JIA; SUI; CHEN, 2013; CETRA; FERREIRA, 2016). Para usá-los como bons indicadores da qualidade ambiental dos recursos aquáticos é relevante conhecer a estrutura das comunidades e informaçóes biológicas das espécies como os hábitos alimentares e utilização do habitat (ESTEVES; ARANHA, 1999).

Neste estudo, um IIB foi adaptado baseado em comunidades de peixes de riachos na sub-bacia do Alto Rio Sorocaba.

\section{MATERIAL E MÉTODOS}

\section{Caracterizaçáo da área}

O trabalho foi desenvolvido em riachos da sub-bacia Alto Sorocaba, componente da Bacia Hidrográfica do Rio Sorocaba e Médio Tietê - SMT (UGRHI 10). A sub-bacia possui área de $924,49 \mathrm{~km}^{2}$ e é composta pelas cidades de Ibiúna, Piedade, São Roque, Votorantim, Vargem Grande Paulista, Alumínio,
Mairinque e o Distrito de Caucaia do Alto (SÃO PAULO, 2017). De um modo geral, o Alto Sorocaba destaca-se por estar sujeito à múltiplas demandas de água, possuir o reservatório de Itupararanga que é a principal fonte manancial da região, além da maior concentração de Áreas de Preservação Permanente (APPs) de nascentes (INSTITUTO DE PESQUISAS TECNOLÓGICAS, 2008). Um total de 8 trechos de riachos foram avaliados com coletas de peixes e tomada de informaçóes ambientais, sendo 3 trechos de riachos no município de São Roque em 2015 e 5 trechos em Ibiúna em 2010 (Figura 1). A captura dos peixes foi realizada uma única vez em cada trecho de 70 metros, utilizando-se equipamento de pesca elétrica, modelo backpack LR-24 Smith Root (licença de pesca $n^{\circ}$ 13352-1 SISBIO/IBAMA/MMA).

\section{Índice Físico de Habitat (IFH)}

Para avaliar as características da estrutura física dos riachos e variáveis da água foi aplicado um Índice Físico de Habitat (IFH) (BARBOUR et al., 1999) (Tabela 1). Foram utilizadas as seguintes métricas: estabilidade do substrato, variabilidade na velocidade e na profundidade, estabilidade do fluxo, combinaçóes de poçóes, rápidos e corredeiras, cobertura vegetal e estabilidade das margens.

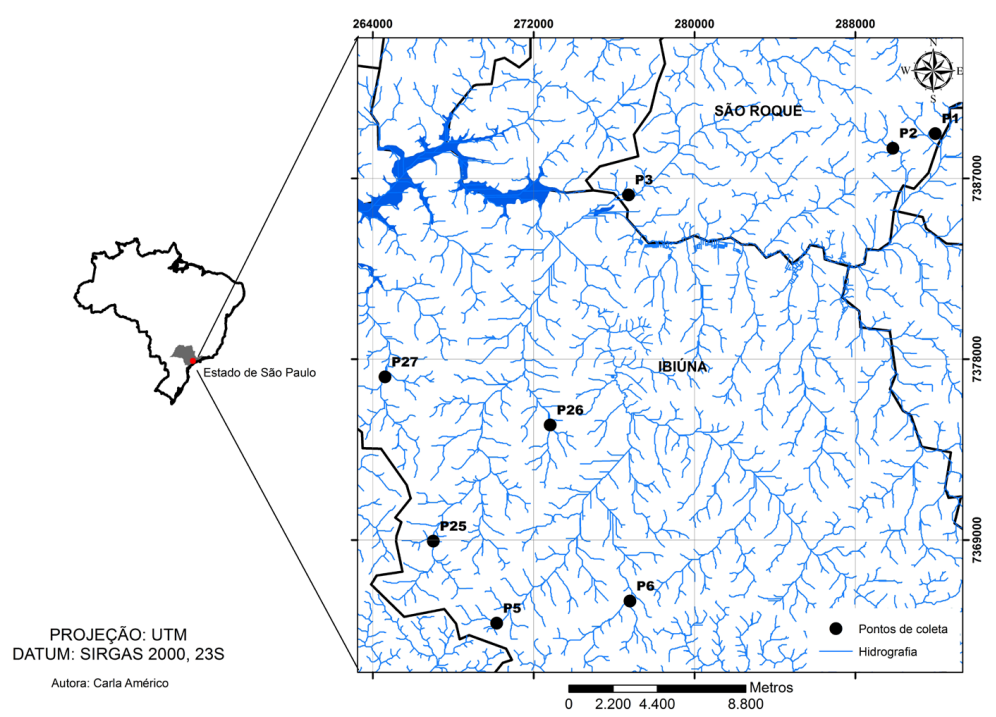

Figura 1: Pontos de coleta dos riachos na sub-bacia Alto Sorocaba. 
Tabela 1: Valores e respectivas características dos descritores que compóem o Índice Físico de Hábitat (IFH), modificado de Barbour et al. (1999).

\begin{tabular}{|c|c|c|c|c|}
\hline Descritor & Bom & Regular & Pobre & Muito Pobre \\
\hline $\begin{array}{l}\text { 1. Estabilidade } \\
\text { do substrato }\end{array}$ & $\begin{array}{l}>70 \% \text { do substrato } \\
\text { favorável à colonização; } \\
\text { mistura de troncos e } \\
\text { galhos submersos ou } \\
\text { outros substratos estáveis } \\
\text { como grandes rochas. }\end{array}$ & $\begin{array}{l}40 \text { a } 70 \% \text { de substrato } \\
\text { favorável à colonização. } \\
\text { Presença de substratos } \\
\text { adicionais recém } \\
\text { caídos. }\end{array}$ & $\begin{array}{l}20 \text { a } 40 \% \text { de substrato } \\
\text { favorável à colonizaçáo } \\
\text { devido a remoçáo de } \\
\text { substratos favoráveis. }\end{array}$ & $\begin{array}{l}<20 \% \text { de substratos } \\
\text { estáveis. Ausência óbvia } \\
\text { de hábitats. }\end{array}$ \\
\hline $\begin{array}{l}\text { 2. Variabilidade } \\
\text { na velocidade e } \\
\text { na profundidade }\end{array}$ & $\begin{array}{l}\text { Presença dos } 4 \text { tipos } \\
\text { de combinaçóes: } \\
\text { Lento/Fundo; Lento/Raso; } \\
\text { Rápido/Fundo e } \\
\text { Rápido/Raso. }\end{array}$ & $\begin{array}{l}3 \text { dos } 4 \text { padróes } \\
\text { presentes. }\end{array}$ & $\begin{array}{l}2 \text { dos } 4 \text { padrões } \\
\text { presentes. }\end{array}$ & $\begin{array}{l}\text { Dominado por } \\
\text { apenas um tipo de } \\
\text { configuração (em geral } \\
\text { Lento/Fundo). }\end{array}$ \\
\hline $\begin{array}{l}\text { 3. Estabilidade } \\
\text { do fluxo }\end{array}$ & $\begin{array}{l}\text { A água alcança a altura } \\
\text { dos bancos laterais. } \\
\text { Mínimo de substrato } \\
\text { exposto no leito do canal. }\end{array}$ & $\begin{array}{l}\text { A água alcança } 75 \% \text { do } \\
\text { canal em potencial. }\end{array}$ & $\begin{array}{l}\text { A água alcança de } \\
25 \text { a } 75 \% \text { do canal em } \\
\text { potencial, deixando } \\
\text { parte do leito exposto. }\end{array}$ & $\begin{array}{l}\text { Pouca água no canal, a } \\
\text { maioria composta por } \\
\text { pequenas poças. }\end{array}$ \\
\hline $\begin{array}{l}\text { 4. Combinação } \\
\text { de poçóes, } \\
\text { rápidos e } \\
\text { corredeiras }\end{array}$ & $\begin{array}{l}\text { Presença de rápidos, } \\
\text { corredeiras e pequenos } \\
\text { poços marginais. }\end{array}$ & $\begin{array}{l}\text { Rápidos mais } \\
\text { predominantes que } \\
\text { corredeiras e pequenos } \\
\text { poços. }\end{array}$ & $\begin{array}{l}\text { Rápidos, poucas } \\
\text { corredeiras e pequenos } \\
\text { poços. }\end{array}$ & Apenas rápidos. \\
\hline I - Escala & $\begin{array}{lllll}20 & 19 & 18 & 17 & 16 \\
\end{array}$ & $\begin{array}{lllll}15 & 14 & 13 & 12 & 11 \\
\end{array}$ & $\begin{array}{llllll}1 & 0 & 9 & 8 & 7 & 6 \\
\end{array}$ & $\begin{array}{lllll}5 & 4 & 3 & 2 & 1 \\
\end{array}$ \\
\hline $\begin{array}{l}\text { 5. Cobertura } \\
\text { vegetal }\end{array}$ & $\begin{array}{l}\text { Vegetação ripária } \\
\text { preservada, acima } \\
\text { de } 20 \mathrm{~m} \text { de largura } \\
\text { para ambas as } \\
\text { margens. Nível de } \\
\text { sombreamento acima } \\
\text { de } 76 \% \text {. }\end{array}$ & $\begin{array}{l}\text { Vegetaçáo ripária } \\
\text { preservada ou } \\
\text { parcialmente } \\
\text { preservada entre } \\
16 \text { e } 20 \mathrm{~m} \text { de } \\
\text { extensão para ambas } \\
\text { as margens. Nível de } \\
\text { sombreamento entre } \\
51 \text { e } 100 \% \text {. }\end{array}$ & $\begin{array}{l}\text { Vegetação ripária } \\
\text { preservada ou } \\
\text { parcialmente } \\
\text { preservada com } \\
6 \text { a } 14 \text { m para ambas } \\
\text { as margens. Nível de } \\
\text { sombreamento entre } \\
26 \text { e } 50 \% \text {. }\end{array}$ & $\begin{array}{l}\text { Vegetação ripária } \\
\text { preservada ou } \\
\text { parcialmente desmatada } \\
\text { com até } 5 \mathrm{~m} \text { ou } \\
\text { vegetação natural } \\
\text { ausente, completamente } \\
\text { substituída por pasto, } \\
\text { agricultura e/ou } \\
\text { ocupação urbana. Nível } \\
\text { de sombreamento entre } \\
0 \text { e } 25 \% \text {. }\end{array}$ \\
\hline $\begin{array}{l}\text { 6. Estabilidade } \\
\text { das margens }\end{array}$ & $\begin{array}{l}\text { Estável. } 0 \text { a } 10 \% \text { de } \\
\text { evidência de erosão. }\end{array}$ & $\begin{array}{l}\text { Moderadamente } \\
\text { estável. } 10 \text { a } 30 \% \text { do } \\
\text { trecho apresentando } \\
\text { áreas de erosão. }\end{array}$ & $\begin{array}{l}\text { Moderadamente } \\
\text { instável. } 30 \text { a } 50 \% \text { das } \\
\text { margens com áreas de } \\
\text { erosão. Alto potencial } \\
\text { erosivo em épocas de } \\
\text { cheias. }\end{array}$ & $\begin{array}{l}\text { Instável. Acima de } \\
50 \% \text { de áreas erodidas. }\end{array}$ \\
\hline $\begin{array}{l}\text { II - Esc } \\
\text { cada ma }\end{array}$ & 10 & 6 & $\begin{array}{lll}5 & 4 & 3\end{array}$ & 2 \\
\hline
\end{tabular}

\section{Classificação das espécies}

Cada espécie foi classificada conforme suas características quanto à sua origem nativa ou exótica; sua posição na coluna d'água: i) nectônica, quando se movem livremente na coluna d'água, ii) bentônica, quando vivem associadas ao substrato ou iii) de superfície, quando circulam na superfície; sua categoria trófica: piscívora (alimenta-se de outros peixes), insetívora (alimentam-se basicamente de insetos), omnívora (peixes que ingerem alimentos diversificados incluindo invertebrados e algas) e 
detritívora (alimentam-se, sobretudo, de detritos de materiais orgânicos) (ESTEVES; ARANHA, 1999; ABELHA; AGOSTINHO; GOULART, 2001; CASATTI, 2002; MANNA; REZENDE; MAZZONI, 2013; CETRA; FERREIRA, 2016).

\section{Desenvolvimento do Índice de Integridade Biótica '(IIB)}

Foram avaliadas 27 métricas com a finalidade de verificar as características da estrutura das comunidades de peixes dos riachos (Tabela 2). As métricas candidatas foram avaliadas quanto à amplitude, capacidade de resposta e redundância. As métricas foram rejeitadas quando mais de $50 \%$ dos seus valores foram iguais a zero (amplitude). Em seguida, foram rejeitadas as variáveis que apresentaram o coeficiente de correlação linear $r<0,4$ com o IFH (capacidade de resposta). Finalmente, nos casos em que duas variáveis foram linearmente correlacionadas e apresentaram coeficiente de correlação de Pearson maior ou igual a 0,9, foi mantida apenas uma variável (redundância) (JIA; SUI; CHEN, 2013).

A bacia do Alto Sorocaba possui alteraçôes antrópicas variadas impossibilitando a localização de ambientes naturais preservados que sirvam de referência. Para elaboração dos escores de pontuação para a composiçáo do IIB utilizamos as melhores condiçôes encontradas em nosso conjunto de dados "the best observed condition criteria" (JENNINGS;

Tabela 2: Variáveis candidatas para o Índice de Integridade Biótica e a resposta esperada com o aumento da degradação ambiental (adaptado de CETRA; FERREIRA, 2016).

\begin{tabular}{|c|c|}
\hline Categoria/Métrica & Resposta \\
\hline \multicolumn{2}{|l|}{ Abundância e diversidade de espécies } \\
\hline Riqueza de espécies $(S)$ & Diminui \\
\hline Índice de Dominância de Simpson (D) & Aumenta \\
\hline Índice de Margalef $(\mathrm{Mg})$ & Diminui \\
\hline Índice de Diversidade alfa (alfa) & Diminui \\
\hline Estatística W da curva $\mathrm{ABC}(\mathrm{W})$ & Diminui \\
\hline Proporção de Riqueza de Characiformes (Scha) & Diminui \\
\hline Número de Characiformes (Ncha) & Diminui \\
\hline Biomassa de Characiformes (Bcha) & Diminui \\
\hline Riqueza de Siluriformes (Ssil) & Diminui \\
\hline Número de Siluriformes (Nsil) & Diminui \\
\hline Biomassa de Siluriformes (Bsil) & Diminui \\
\hline Riqueza de Loricariidae (Sloricar) & Diminui \\
\hline Número de Loricariidae (Nloricar) & Diminui \\
\hline Biomassa de Loricariidae (Bloricar) & Diminui \\
\hline \multicolumn{2}{|l|}{ Uso de habitat } \\
\hline Riqueza espécies de corredeiras e poçóes (Sspcorre) & Diminui \\
\hline Número de espécies de corredeiras e poçôes (Nspcorre) & Diminui \\
\hline Biomassa de espécies de corredeiras e poçóes (Bspcorre) & Diminui \\
\hline \multicolumn{2}{|l|}{ Estrutura Trófica } \\
\hline Número de categorias tróficas (Tro) & Diminui \\
\hline Riqueza de piscívoros (Spisc) & Diminui \\
\hline Número de indivíduos píscivoros (Npisc) & Diminui \\
\hline Biomassa de piscívoros (Bpisc) & Diminui \\
\hline Riqueza de insetívoros (Sins) & Diminui \\
\hline Número de indivíduos insetívoros (Nins) & Diminui \\
\hline Biomassa de insetívoros (Bins) & Diminui \\
\hline Riqueza de onívoros (Soni) & Aumenta \\
\hline Número de indivíduos onívoros (Noni) & Aumenta \\
\hline Biomassa de onívoros (Boni) & Aumenta \\
\hline
\end{tabular}


FORE; KARR, 1995; MCDONOUGH; HICKMAN, 1999; STODDARD et al., 2006; PETESSE; PETRERE JUNIOR; AGOSTINHO, 2014). Os valores encontrados nos pontos para cada métrica selecionada foram agrupados e divididos em percentis, sendo acima do valor $66^{\circ}$ foi dada a pontuação 5 e abaixo de $33^{\circ}$ a pontuação 1 . Valores intermediários receberam pontuação 3. Para as métricas negativamente relacionadas ao grau de interferência antrópica foi definido o valor 1 acima do percentil $66^{\circ}$ e 5 abaixo do percentil $33^{\circ}$. O IIB foi calculado a partir da soma da pontuação das métricas.

\section{RESULTADOS}

Foram coletados 791 peixes, sendo distribuídos em seis ordens, oito 8 famílias e 21 espécies. Dentre eles, 99,8\% são nativos, sendo apenas Australoheros facetus uma espécie exótica à bacia do rio Sorocaba. Quanto à posição das espécies na coluna d'água, 61,9\% são nectônicas, 33,3\% bentônicas e 4,7\% de superfície. Para categorias tróficas, $47,6 \%$ das espécies são omnívoras, 33,3\% insetívoras, $14,2 \%$ piscívoras e $4,7 \%$ detritívoras. A espécie Phaloceros reisi, comumente encontrada em locais degradados, representou $46 \%$ do total de indivíduos coletados, seguida por Astyanax fasciatus com 13,9\% (Tabela 3).

Das 27 métricas inicialmente propostas, 9 foram rejeitadas por apresentarem mais de $50 \%$ de seus valores iguais a zero. Das 18 restantes, 12 foram removidas levando-se em consideração a capacidade de resposta (Tabela 4). Das 6 métricas remanescentes, proporção de biomassa de siluriformes (Bsil) foi excluída pois foi considerada redundante com proporção do número de siluriformes (Nsil). Proporção da biomassa de omnívoros

Tabela 3: Abundância das espécies capturadas $(\mathrm{N})$ e classificação de acordo com origem, posição na coluna de água e categoria trófica.

\begin{tabular}{|c|c|c|c|c|}
\hline FAMÍLIA/ESPÉCIE & $\mathrm{N}$ & Origem & $\begin{array}{c}\text { Posição na } \\
\text { coluna d'água }\end{array}$ & $\begin{array}{c}\text { Categoria } \\
\text { trófica }\end{array}$ \\
\hline \multicolumn{5}{|l|}{ Characiformes } \\
\hline Astyanax altiparanae Garutti \& Britski, 2000 & 4 & nativo & nectonico & omnívoro \\
\hline Astyanax biotae Castro \& Vari, 2004 & 1 & nativo & nectonico & omnívoro \\
\hline Astyanax bockmanni Vari \& Castro, 2007 & 16 & nativo & nectonico & omnívoro \\
\hline Astyanax fasciatus Cuvier, 1819 & 110 & nativo & nectonico & omnívoro \\
\hline Astyanax scabripinnis Eigenmann, 1908 & 24 & nativo & nectonico & omnívoro \\
\hline Hoplias malabaricus Bloch, 1794 & 10 & nativo & nectonico & piscívoro \\
\hline Hyphessobrycon anisitsi Eigenmann, 1907 & 15 & nativo & nectonico & omnívoro \\
\hline Oligosarcus paranaensis Menezes \& Géry, 1983 & 3 & nativo & nectonico & insetívoro \\
\hline Bryconamericus iheringii Boulenger, 1887 & 44 & nativo & nectonico & omnívoro \\
\hline \multicolumn{5}{|l|}{ Cyprinodontiformes } \\
\hline Phalloceros reisi Lucinda, 2008 & 364 & nativo & superfície & detritívoro \\
\hline \multicolumn{5}{|l|}{ Gymnotiformes } \\
\hline Gymnotus carapo Linnaeus, 1758 & 1 & nativo & nectonico & insetívoro \\
\hline Gymnotus sylvius Albert \& Fernandes-Matioli, 1999 & 2 & nativo & nectonico & insetívoro \\
\hline \multicolumn{5}{|l|}{ Perciformes } \\
\hline Australoheros facetus Jenyns, 1842 & 1 & Exótico & nectonico & píscivoro \\
\hline Geophagus brasiliensis Quoy \& Gaimard, 1824 & 91 & nativo & nectonico & omnívoro \\
\hline \multicolumn{5}{|l|}{ Siluriformes } \\
\hline Callichthys callichthys Linnaeus, 1758 & 2 & nativo & bentonico & omnívoro \\
\hline Corydoras aeneus Gill, 1858 & 4 & nativo & bentonico & omnívoro \\
\hline Hypostomus ancistroides Ihering, 1911 & 13 & nativo & bentonico & insetívoro \\
\hline Pimelodella avanhandavae Eigenmann, 1917 & 13 & nativo & bentonico & insetívoro \\
\hline Pimelodella meeki Eigenmann, 1910 & 61 & nativo & bentonico & insetívoro \\
\hline Rhamdia quelen Quoy \& Gaimard, 1824 & 8 & nativo & bentonico & insetívoro \\
\hline \multicolumn{5}{|l|}{ Synbranchiformes } \\
\hline Synbranchus marmoratus Bloch, 1795 & 4 & nativo & bentonico & piscívoro \\
\hline
\end{tabular}


Tabela 4: Valores das métricas. Métricas rejeitadas: $+>50 \%$ dos valores iguais a zero e $++\mathrm{r}<0,4$ com IFH.

\begin{tabular}{|c|c|c|c|c|c|c|c|c|}
\hline Métricas/pontos & $\mathrm{P} 1$ & $\mathrm{P} 2$ & P3 & P4 & P5 & P6 & P7 & P8 \\
\hline$S(++)$ & 1 & 11 & 7 & 9 & 8 & 7 & 9 & 7 \\
\hline $\mathrm{D}(++)$ & 1 & 0,16 & 0,65 & 0,52 & 0,39 & 0,33 & 0,19 & 0,25 \\
\hline $\operatorname{Mg}(++)$ & 0 & 2,64 & 0,96 & 1,48 & 1,37 & 1,26 & 1,95 & 1,75 \\
\hline alfa $(++)$ & 0,16 & 4,33 & 1,27 & 1,89 & 1,76 & 1,64 & 2,94 & 2,82 \\
\hline $\mathrm{W}(++)$ & 0 & $-0,19$ & 0,04 & $-0,18$ & $-0,03$ & $-0,01$ & 0,02 & 0,07 \\
\hline Scha $(++)$ & 0 & 0,45 & 0,43 & 0,44 & 0,38 & 0,29 & 0,56 & 0,43 \\
\hline Ncha $(++)$ & 0 & 0,55 & 0,31 & 0,20 & 0,18 & 0,52 & 0,55 & 0,26 \\
\hline Bcha $(++)$ & 0 & 0,47 & 0,18 & 0,49 & 0,29 & 0,48 & 0,35 & 0,10 \\
\hline Ssil & 0 & 0,18 & 0,29 & 0,33 & 0,25 & 0,29 & 0,11 & 0,43 \\
\hline Nsil & 0 & 0,24 & 0,64 & 0,03 & 0,01 & 0,05 & 0,05 & 0,61 \\
\hline Bsil & 0 & 0,27 & 0,79 & 0,20 & 0,01 & 0,04 & 0,04 & 0,89 \\
\hline Sloricar (+) & 0 & 0 & 0 & 0,11 & 0,13 & 0,14 & 0,11 & 0 \\
\hline Nloricar (+) & 0 & 0 & 0 & 0,02 & 0,01 & 0,04 & 0,05 & 0 \\
\hline Bloricar (+) & 0 & 0 & 0 & 0,04 & 0 & 0,02 & 0,04 & 0 \\
\hline Sspcorre (+) & 1 & 0,82 & 0,71 & 0 & 0 & 0 & 0 & 0 \\
\hline Nspcorre (+) & 1 & 0,76 & 0,36 & 0 & 0 & 0 & 0 & 0 \\
\hline Bspcorre (+) & 1 & 0,73 & 0,21 & 0 & 0 & 0 & 0 & 0 \\
\hline Tro & 1 & 4 & 3 & 3 & 3 & 3 & 3 & 3 \\
\hline Spisc $(++)$ & 0 & 0,09 & 0 & 0,22 & 0,13 & 0,43 & 0,22 & 0,14 \\
\hline Npisc (++) & 0 & 0,04 & 0 & 0,01 & 0,01 & 0,05 & 0,07 & 0,06 \\
\hline Bpisc $(++)$ & 0 & 0,14 & 0 & 0,17 & 0,07 & 0,20 & 0,38 & 0,43 \\
\hline Sins $(+)$ & 0 & 0,45 & 0,29 & 0 & 0 & 0 & 0 & 0,14 \\
\hline Nins (+) & 0 & 0,37 & 0,64 & 0 & 0 & 0 & 0 & 0,42 \\
\hline Bins $(+)$ & 0 & 0,59 & 0,79 & 0 & 0 & 0 & 0 & 0,39 \\
\hline Soni & 1 & 0,36 & 0,57 & 0,67 & 0,75 & 0,43 & 0,67 & 0,71 \\
\hline Noni & 1 & 0,49 & 0,32 & 0,97 & 0,98 & 0,91 & 0,88 & 0,52 \\
\hline Boni & 1 & 0,26 & 0,21 & 0,79 & 0,93 & 0,78 & 0,57 & 0,18 \\
\hline
\end{tabular}

(Boni) foi excluída considerada redundante com proporção do número de omnívoros (Noni). As métricas proporção do número de omnívoros (Noni) e proporção do número de siluriformes (Nsil) são redundantes, demonstraram uma forte correlação inversamente proporcional $(-0,91)$, mas serão mantidas no IIB devido à importância da resposta destas métricas para o estudo.

Quatro métricas compuseram o IIB e foram pontuadas para a classificação em categorias (Tabela 5).
As métricas finais incluíram as categorias abundância e diversidade de espécies e estrutura trófica, sendo estas: proporção da riqueza de siluriformes (Ssil), proporção do número de indivíduos siluriformes (Nsil), proporção do número de indivíduos omnívoros (Soni) e o número de categorias tróficas (Ntrof). A integridade biótica foi classificada como boa em 37,5\% dos pontos, regular em $50 \%$ e em $12,5 \%$ dos casos a integridade biológica foi muito pobre (Tabela 6). 
Tabela 5: Pontuação obtida no IIB a partir do valor encontrado em cada atributo para o Sorocaba e Médio Tietê.

\begin{tabular}{lccc}
\hline \multicolumn{1}{c}{ Categoria/Métrica } & Pontuação & \\
\hline Composição e riqueza de espécies & $\mathbf{5}$ & $\mathbf{3}$ & $\mathbf{1}$ \\
Proporção da riqueza de Siluriformes (Ssil) & $>0,29$ & $0,18-0,29$ & $<0,18$ \\
Proporção do número indivíduos Siluriformes (Nsil) & $>0,24$ & $0,03-0,24$ & $<0,03$ \\
Composiçáo trófica & & & \\
Proporção de indivíduos do hábito alimentar omnívoro (Noni) & $<0,52$ & $0,52-0,97$ & $>0,97$ \\
Número de categorias tróficas (Ntrof) & $>3$ & 3 & $<3$ \\
\hline
\end{tabular}

Tabela 6: Descrição da integridade biótica dos riachos, valores de IIB e quantidade de riachos encontrados na categoria $(\mathrm{n})$.

\begin{tabular}{|c|c|c|c|}
\hline Categoria & Pontuação & Descrição & $\mathrm{n}$ \\
\hline Excelente & $17-20$ & $\begin{array}{l}\text { Comparável à melhor situaçáo sem perturbaçóes humanas; a contribuição } \\
\text { relativa dos indivíduos como Siluriformes é alta, sem omnívoros. }\end{array}$ & 0 \\
\hline Boa & $13-16$ & $\begin{array}{l}\text { A comunidade de peixe representada por indivíduos como Siluriformes e } \\
\text { detritívoros/insetívoros/piscívoros; estrutura trófica mostra alguns sinais de } \\
\text { estresse. }\end{array}$ & 3 \\
\hline Regular & $9-12$ & $\begin{array}{l}\text { Sinais de deterioraçáo adicional incluem perda de indivíduos } \\
\text { como siluriformes e estrutura trófica alterada, com freqüência crescente de } \\
\text { omnívoros. }\end{array}$ & 4 \\
\hline Pobre & $5-8$ & $\begin{array}{l}\text { Comunidade de peixes dominada por omnívoros com menos abundância } \\
\text { de indivíduos siluriformes. }\end{array}$ & 0 \\
\hline Muito Pobre & $1-4$ & Predominância de omnívoros & 1 \\
\hline Sem peixes & 0 & Sem captura de qualquer peixe. & 0 \\
\hline
\end{tabular}

\section{DISCUSSÃO}

Em riachos com boa integridade biótica na região é esperado encontrar elevada abundância de espécies da ordem Siluriformes e baixa proporção de indivíduos omnívoros. Espera-se encontrar espécies da ordem Siluriformes em ambientes mais conservados, mas quando há ocorrência de impactos ambientais antropogênicos, outras ordens podem dominar no local como os Cyprinodontiformes, que apresenta espécies tolerantes à degradação ambiental (CASTRO et al., 2003; CASATTI et al., 2006).

De maneira geral, o IIB foi crescente entre os pontos à medida em que o número de omnívoros se reduziu, seguindo um padrão conforme ocorrência de alteraçóes no ambiente. Estes resultados permitiram adaptar um Índice de Integridade Biótica - IIB que reflete de forma satisfatória o gradiente ambiental referente à diversidade e estrutura trófica da ictiofauna da sub-bacia, mas pode não detectar devidamente as mudanças ambientais referentes à composição e uso do habitat das espécies no ambiente devido à ausência de fatores diretamente relacionados a esses atributos. Nenhum dos locais estudados no Alto Sorocaba obteve pontuação para definir-se como IIB “excelente”, indicando que muitos aspectos da integridade biológica estão alterados, em contrapartida, com quase $40 \%$ dos pontos enquadrados na categoria "Boa", ainda existem pontos que podem ser utilizados como referência.

Os riachos de boa integridade biótica expressam características ambientais favoráveis como boa cobertura vegetal no local, estabilidade das margens com poucas evidências de erosão e variação da velocidade e profundidade, proporcionando micro-habitats que fornecem refúgio e alimentação favoráveis à manutenção de certas espécies como as nectônicas 
(61,9\% da amostra) que exploram a coluna d'água com mais mobilidade e náo dependem do substrato para se alimentar, podendo ser um indicador de ambiente conservado (KARR, 1981).

Os valores de IIB encontrados neste estudo evidenciam as influências das alteraçóes na estrutura física do habitat dos riachos, principalmente associando-se tais modificaçóes ao substrato instável dos pontos, avaliados entre 'pobre' e 'muito pobre'. Isso indica que impactos podem estar ocorrendo nesses ambientes e podem afetar a permanência e manutenção das espécies encontradas. Segundo Ferreira e Casatti (2006), a presença da vegetação ripária favorece a ocorrência de espécies que dependem do material vegetal alóctone para se alimentar. Em boas condiçóes, a vegetação ripária é extremamente relevante para manutenção das espécies aquáticas e para manter a qualidade ambiental nos ambientes (CETRA, 2003). Portanto, podemos perceber que mesmo com a instabilidade do substrato as espécies podem sobreviver desde que a mata ripária esteja estruturada para mantê-las no ambiente.

\section{CONCLUSÃO}

O índice de integridade biótica adaptado mostrou-se útil ao selecionar uma pequena quantidade de métricas bióticas que responderam ao gradiente ambiental, revelando-se uma boa ferramenta para ser utilizada em um futuro monitoramento biológico e conservação da biodiversidade a longo prazo e com baixo custo.

\section{REFERÊNCIAS}

ABELHA, M. C. F.; AGOSTINHO, A. A.; GOULART, E. Plasticidade trófica em peixes de água doce. Acta Scientiarum, Maringá, v. 23, n. 2, p. 425-434, 2001.

AGOSTINHO, A. A.; THOMAZ, S. M.; GOMES, L. C. Conservação da biodiversidade em águas continentais do Brasil. Megadiversidade, Belo Horizonte, v. 1, n. 1, p. 70-78, 2005.

BARBOUR, M. T. et al. EPA 841-B-99-002: bioavaliação rápida protocolos para uso em córregos e rios: perifiton, bentônicos, coletas da fauna e peixes. 2. ed. Washington: Agência de Proteção Ambiental, Escritório de Água, 1999.

CASATTI, L. Alimentação dos peixes em um riacho do Parque Estadual Morro do Diabo, bacia do Alto Rio Paraná, sudeste do Brasil. Biota Neotropica, Campinas, v. 2, n. 2, p. 1-14, 2002. http://dx.doi.org/10.1590/ S1676-06032002000200012.
CASATTI, L. et al. Stream fishes, water and habitat quality in a pasture dominated basin, southeastern Brazil. Brazilian Journal of Biology = Revista Brasileira de Biologia, São Carlos, v. 66, n. 2b, p. 29-41, 2006. http://dx.doi.org/10.1590/S1519-69842006000400012.

CASATTI, L.; FERREIRA, C. P.; CARVALHO, F. R. Grass-dominated stream sites exhibit low fish species diversity and dominance by guppies: an assessment of two tropical pasture river basins. Hydrobiologia, Dordrecht, v. 632, n. 1, p. 273-283, 2009. http://dx.doi.org/10.1007/ s10750-009-9849-y.

CASATTI, L. et al. From forests to cattail: how does the riparian zone influence stream fish? Neotropical /chthyology, Porto Alegre, v. 10, n. 1, p. 205-214, 2012. http://dx.doi.org/10.1590/S1679-62252012000100020.

CASTRO, R. M. C. et al. Estrutura e composição da ictiofauna de riachos do Rio Paranapanema, sudeste e sul do Brasil. Biota Neotropica, Campinas, v. 3, n. 1, p. 1-31, 2003. http://dx.doi.org/10.1590/S167606032003000100007.

CETRA, M. Caracterização das assembléias de peixes da Bacia do Rio Corumbataí (SP). 200388 p. Tese (Doutorado em Ciências da Engenharia Ambiental) - Escola de Engenharia de São Carlos, Universidade de São Paulo, São Carlos, 2003.

CETRA, M.; FERREIRA, F. C. Fish-based Index of Biotic Integrity for wadeable streams from Atlantic Forest of south São Paulo State, Brazil. Acta Limnologica Brasiliensia, Rio Claro, v. 28, n. e-22, 2016.

ESTEVES, K. E.; ALEXANDRE, C. V. Development of an index of biotic integrity based on fish communities to assess the effects of rural and urban land use on a stream in southeastern Brazil. International Review of Hydrobiology, Berlin, v. 96, n. 3, p. 296-317, 2011. http:// dx.doi.org/10.1002/iroh.201111297.

ESTEVES, K. E.; ARANHA, J. M. R. Ecologia trófica de peixes de riachos. Oecologia Brasiliensis, Rio de Janeiro, v. 6, p. 157-182, 1999.

FERREIRA, C. P.; CASATTI, L. Integridade biótica de um córrego na bacia do Alto Rio Paraná avaliada por meio da comunidade de peixes. Biota Neotropica, Campinas, v. 6, n. 3, p. 1-25, 2006. http://dx.doi. org/10.1590/S1676-06032006000300002.

INSTITUTO DE PESQUISAS TECNOLÓGICAS - IPT. Plano de bacia da unidade de gerenciamento de recursos hídricos do Sorocaba e Médio Tietê (UGRHI 10). 2008. Disponivel em: <http://www.sigrh.sp.gov.br/ public/uploads/documents/7099/smt_rpb.pdf>. Acesso em: 25 mar. 2016.

JENNINGS, M. J.; FORE, L. S.; KARR, J. R. Biological monitoring of fish assemblages in Tennessee Valley reservoirs. Regulated Rivers: Research and Management, New York, v. 11, n. 3-4, p. 263-274, 1995. http://dx.doi.org/10.1002/rrr.3450110303. 
JIA, Y. T.; SUI, X. Y.; CHEN, Y. F. Development of a fish-based index of biotic integrity for wadeable streams in Southern China. Environmental Management, Ottawa, v. 52, n. 4, p. 995-1008, 2013. http://dx.doi. org/10.1007/s00267-013-0129-2.

KARR, J. R. Assessment of biotic integrity using fish communities. Fisheries, Bethesda, v. 6, n. 6, p. 21-27, 1981. http://dx.doi.org/10.1577/15488446(1981)006<0021:AOBIUF>2.0.CO;2.

MANNA, L. R.; REZENDE, C. F.; MAZZONI, R. Diversidade funcional de peixes de riacho: como as assembleias podem estar organizadas? Oecologia Australis, Rio de Janeiro, v. 17, n. 3, p. 402-410, 2013. http:// dx.doi.org/10.4257/oeco.2013.1703.08.

MARCIANO, F. T.; CHAUDHRY, F. H.; RIBEIRO, M. C. Evaluation of the index of biotic integrity in the Sorocaba river basin (Brazil, SP) based on fish communities. Acta Limnologica Brasiliensia, Rio Claro, v. 16 , n. 3, p. 225-237, 2004.

MCDONOUGH, T. A.; HICKMAN, G. D. Reservoir fish assemblage index development: a tool for assessing ecological health in tennessee valley authority impoundments. In: SIMON, T. P. (Org.). Assessing the sustainability and biological integrity of water resources using fish communities. Boca Raton: CRC Press, 1999. p. 523-540.

PETESSE, M. L.; PETRERE JUNIOR, M.; AGOSTINHO, A. A. Defining a fish bio-assessment tool to monitoring the biological condition of a cascade reservoirs system in tropical área. Ecological Engineering, Oxford, v. 69, p. 139-150, 2014. http://dx.doi.org/10.1016/j.ecoleng.2014.03.070.

SÃO PAULO. Comitê de Bacias Hidrográficas do Rio Sorocaba e Médio Tietê - CBH-SMT. Secretaria Executiva do Comitê de Bacias Sorocaba e Médio Tietê. Relatório de situação 2017: ano base 2016. 2017. Disponível em: <http://www.sigrh.sp.gov.br/public/uploads/ events//CBH-SMT/4566/8relatorio-situao-22062017---simplificado. pdf>. Acesso em: 18 nov. 2016.

STODDARD, J. L. et al. Setting expectations for the ecological condition of streams: the concept of reference condition. EcologicalApplications, Tempe, v. 16, n. 4, p. 1267-1276, 2006. http://dx.doi.org/10.1890/10510761(2006)016[1267:SEFTEC]2.0.CO;2. em Planejamento e Uso de Recursos Naturais (PPGPUR), Universidade Federal de São Carlos - UFSCar, Rodovia João Leme dos Santos, Km 110, CEP 18052-780, Sorocaba, SP, Brazil marienergia@gmail.com

Contribuição do autor

Pesquisa em campo e coleta de dados. Transformação da dissertaçáo de mestrado em artigo. Escrita do artigo.

Maurício Cetra

Departamento de Ciências Ambientais, Universidade Federal de São Carlos - UFSCar, Rodovia João Leme dos Santos, Km 110, CEP 18052-780, Sorocaba, SP, Brazil maucetra@gmail.com

Contribuição do autor

Implementação da ferramenta de adaptação do Índice de Integridade Biótica Pesquisa de campo e coleta de dados. Auxílio na escrita do artigo. 